Using Raman spectroscopy to understand the origin of the phase transition observed in the crystalline sulfur based amino acid I-methionine

Lima, José A.; Freire, P.T.C.; Melo, F.E.A.; Mendes-Filho, J.; Fischer, Jennifer ; Havenith, Remco W.A.; Broer, R.; Bordallo, Heloisa N.

Published in:

Vibrational Spectroscopy

DOI:

10.1016/j.vibspec.2012.12.004

Publication date:

2013

Document version

Early version, also known as pre-print

Citation for published version (APA):

Lima, J. A., Freire, P. T. C., Melo, F. E. A., Mendes-Filho, J., Fischer, J., Havenith, R. W. A., Broer, R., \&

Bordallo, H. N. (2013). Using Raman spectroscopy to understand the origin of the phase transition observed in the crystalline sulfur based amino acid I-methionine. Vibrational Spectroscopy, 65(March), 132.

https://doi.org/10.1016/j.vibspec.2012.12.004 


\title{
Using Raman spectroscopy to understand the origin of the phase transition observed in the crystalline sulfur based amino acid L-methionine
}

\author{
José A. Lima Jr. ${ }^{a}$, Paulo T.C. Freire ${ }^{a},{ }^{*}$, Francisco E.A. Melo ${ }^{a}, J^{\prime}$ Mendes Filho ${ }^{a}$, Jennifer Fischer ${ }^{b}$, \\ Remco W.A. Havenith ${ }^{\mathrm{c}}$, Ria Broer ${ }^{\mathrm{c}}$, Heloisa N. Bordallo ${ }^{\mathrm{d}}$ \\ a Departamento de Física, Universidade Federal do Ceará, C.P. 6030 Fortaleza-CE 60455-760, Brazil \\ ${ }^{\mathrm{b}}$ Forschungszentrum Jülich, Institut of Complex Systems, 52425 Jülich, Germany \\ c Theoretical Chemistry, Zernike Institute for Advanced Materials, University of Groningen, 9747 AG Groningen, The Netherlands \\ d Niels Bohr Institute, University of Copenhagen, 2100 Copenhagen, Denmark
}

\section{A R T I C L E I N F O}

\section{Article history:}

Received 2 October 2012

Received in revised form 7 December 2012

Accepted 8 December 2012

Available online 20 December 2012

\section{Keywords:}

Vibrational properties

DFT calculations

Phase transition

\begin{abstract}
A B S T R A C T
We present the Raman spectra of L-methionine $\left(\mathrm{C}_{5} \mathrm{H}_{11} \mathrm{NO}_{2} \mathrm{~S}\right)$ monocrystals obtained in the spectral region ranging from 3200 to $50 \mathrm{~cm}^{-1}$ at temperatures from 20 to $375 \mathrm{~K}$. We investigated the dynamics of the different functional groups in L-methionine and related their behaviour to the structural transition previously reported at about $307 \mathrm{~K}$. Additionally, on cooling, changes in the intensities of some Raman bands were associated with conformational changes of at least one of the two L-methionine conformers in the monoclinic unit cell in the interval $160-140 \mathrm{~K}$. Thermal analysis and DFT calculations provide further support to the interpretation of the Raman results.
\end{abstract}

(C) 2012 Elsevier B.V. All rights reserved.

\section{Introduction}

In the past fifteen years, many studies have focused on the vibrational and structural properties of amino acids [1,2]. This is consequence of the fact that these studies can shed light on the dynamics of the functional groups constituting amino acids, the principal building blocks of proteins and enzymes, as well as provides information about $\mathrm{H}$-bonds, which are of fundamental interest in biochemical processes and drug design, among others. Additionally, some research has pointed out the possibility of using crystalline amino acids in technological applications, including nonlinear optics and in the food industry $[3,4]$. Very recently, even one of the most impressive physical properties of solids ferroelectricity - was reported in $\gamma$-glycine [5].

Among the proteic amino acids, two of them have sulfur in their structure: cysteine, $\mathrm{C}_{3} \mathrm{H}_{7} \mathrm{NO}_{2} \mathrm{~S}$, and methionine, $\mathrm{C}_{5} \mathrm{H}_{11} \mathrm{NO}_{2} \mathrm{~S}$. Various studies related to the vibrational and structural properties of both orthorhombic and monoclinic L-cysteine have been reported in the literature [6-13]. From these investigations, several aspects of the material were revealed, including the observation of changes in the orientation of the side group $-\mathrm{CH}-\mathrm{CH}_{2} \mathrm{SH}$, associated with the extended phase transition observed at low temperatures in the orthorhombic polymorph $[8,10]$, the re-orientation of the side

\footnotetext{
* Corresponding author. Tel.: +55 853366 9906; fax: +55 853369450.

E-mail addresses: tarso@fisica.ufc.br, tarsofreire@gmail.com (P.T.C. Freire).
}

groups related to the dynamical transition detected in its monoclinic polymorph [12], as well as different responses to hydrostatic pressure on each polymorph [13]. On the other hand, the physical properties of L-methionine, which has a sulfur atom between two carbons implying that the $\mathrm{H}$-bonds allowed in cysteine are forbidden in methionine, have seen little study. To the best of our knowledge, very few Raman studies have been reported to date for the solid crystalline form of L-methionine. Using unpolarized light, one compared the solid-state spectra at 273 and $323 \mathrm{~K}$ [14], and the other the spectra observed from solid-states samples and water solutions to theoretical spectra of the single-molecules obtained by quantum chemical calculations [15]. Combining IR and Raman spectroscopy to semi-empirical MNDO conformational analysis [14], it was shown that the phase transition observed by means of calorimetric measurements $[16,17]$ on powder samples at about $307 \mathrm{~K}$ is related to the existence of a slightly modified $\mathrm{H}$-bonded double layer giving rise to similar lattice vibrations in both phases. In addition, L-methionine and its N-deuterated isotopomer were characterized by infrared spectroscopy at room temperature in the spectral range $4000-400 \mathrm{~cm}^{-1}$ [18] and a Raman spectroscopic study of L-methionine crystal under high pressure (up to 5 GPa) [19] was also carried out. The latter showed pronounced changes in the Raman spectra, which were associated with a structural phase transition at about $2.2 \mathrm{GPa}$. On the structural side, studies were reported by three groups, one on powder samples [20] and two others using single crystals obtained from slow evaporation of ethanol-water solutions [21] and 2-propanol in 


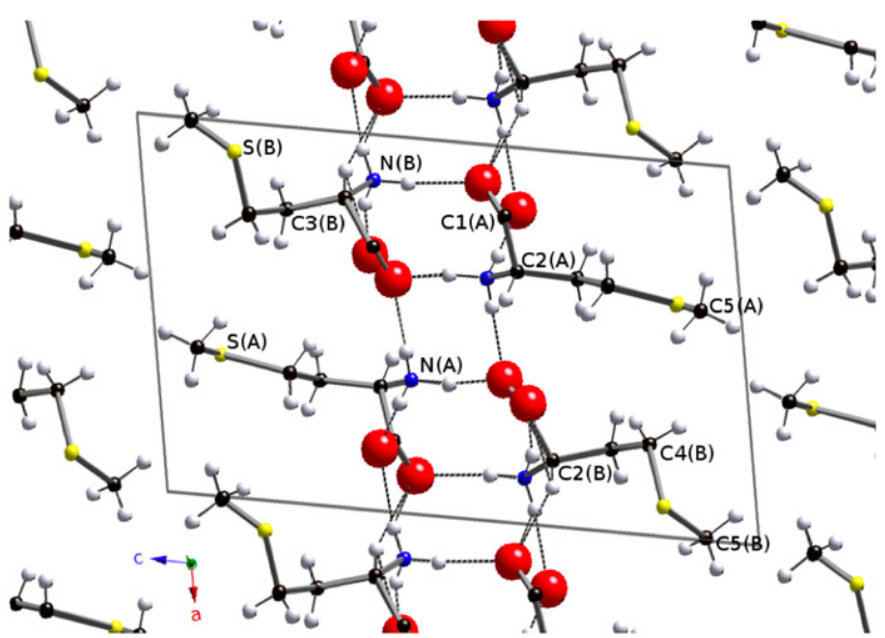

Fig. 1. Crystal structure of L-methionine at $120 \mathrm{~K}$ from X-ray diffraction [22]. Two different molecules ( $\mathrm{A}$ and $\mathrm{B}$ ) with distinct conformation are observed and only some atoms are labeled for clarification. Hydrogen-atoms (white) are on idealized positions.

tetramethoxysilane gel [22], at 300 and $120 \mathrm{~K}$, respectively. All the studies show that L-methionine crystallizes in the monoclinic $P 2_{1}$ space group with four molecules in the unit cell $(Z=4)$, building up a double-layered structure having a hydrophilic and hydrophobic layer. In the hydrophilic layer the $\mathrm{NH}_{3}{ }^{+}$and $\mathrm{CO}_{2}{ }^{-}$head groups are linked through $\mathrm{H}$-bonds, while in the hydrophobic layer the residuals are held together by van-der-Waals forces, as shown in Fig. 1.

The L-form of methionine is considered an essential amino acid, being very important in the process of methylation and also constituting a precursor to other amino acids, such as L-cysteine and homocysteine, which are involved in numerous processes of methyl group transfer and which play fundamental roles in the biochemistry of the human body [23]. It has also been used as supportive supplement in immune-deficient patients [24], and its oxidation has been associated with some neurological disease such as Alzheimer's [25]. Recently L-methionine has attracted interest due its role on the inactivation of Pt complexes and in the treatment with Pt drugs [26]. Interestingly, it has been shown that L-methionine side chains in proteins possess unique structural properties. For instance, the flexibility of the L-methionine side chains provides for a malleable nonpolar surface that can easily adapt to a variety of peptide partners [27]. Moreover, in contrast to other hydrophobic residues, the side chains of L-methionine are unbranched allowing for conformational flexibility [28].

Measuring dynamic properties as a function of temperature constitutes a powerful means of obtaining insight on the strength of atomic interactions. On the experimental side, spectroscopy techniques such as nuclear magnetic resonance, Raman scattering, infrared and inelastic neutron spectroscopies are appropriate probes for studies of $\mathrm{H}$-vibrational dynamics because subtle structural changes that arise from changes in packing density due to variations in intermolecular distances in the H-bond network can be followed without difficulty. In reality, since the first systematic Raman scattering study of amino acids by Edsall [29], Raman scattering has been increasingly used in structural biology investigations, as for instance in the study of conformational characterization of peptides and proteins [30] and protein binding constants [31]. In addition, it has been shown that the combined spectroscopic/crystallographic/thermal analysis approach is a powerful new tool to investigate intermolecular interactions in a variety of hydrogenated systems [32,33], as well as in the simpler amino acids residues $[34,35]$. In the particular case of nonpolar



Fig. 2. The B3LYP/6-31G** optimized geometry of L-methionine.

crystalline amino acids, by using such type of approach it was demonstrated that $\alpha$-glycine and L-isoleucine are stable between 20 and $300 \mathrm{~K}$ [36-38], partially deuterated L-alanine undergoes a solid-solid phase transition around $260 \mathrm{~K}$ followed by conformational change at lower temperatures [39], L-valine undergoes a solid-solid phase transition about $120 \mathrm{~K}$ [40], L-leucine undergoes three solid-solid phase transitions at 150, 275 and $353 \mathrm{~K}$ [41], and interestingly the sulfur containing amino acid L-cysteine undergoes a subtle dynamical transition around $150 \mathrm{~K}$ in its monoclinic form [12] while for the orthorhombic polymorph an extended transition around $70 \mathrm{~K}$ was observed [10]. It is also worth mentioning that many other studies in amino acid, mainly using Raman spectroscopy, have been published in the past years [42-62].

In this work we investigate the Raman spectra of crystalline L-methionine at low and high temperatures. From this study we were able to demonstrate that the phase transition observed in Lmethionine powder samples at $307 \mathrm{~K}$ is a result of the flexibility of the residue side chains. Moreover, through the careful inspection of the evolution of the Raman bands in the high wavenumber region, we were able to identify a conformational change of the molecule at low temperatures. DFT studies enabled us to model the observed Raman vibrations of L-methionine allowing for the assignment of most vibrations at the $\Gamma$ point, while thermal analysis confirmed that the malleability of the L-methionine side chain residues gives rise to an intricate behavior of the H-bond network in this system.

\section{Experimental}

L-Methionine single crystals were grown by slow evaporation of an aqueous solution of a commercial reagent (Sigma) at a typical temperature of $275 \mathrm{~K}$. After $3-4$ weeks, it is possible to obtain crystals as thin elongated plates of diverse sizes. In the Raman experiment the backscattered light was analyzed through a Jobin Yvon Triplemate 64000 micro-Raman system equipped with an $\mathrm{N}_{2}$-cooled CCD detector coupled to a microscope Olympus BX40. The slits give a typical $2 \mathrm{~cm}^{-1}$ spectral resolution. Excitation $(\lambda=514.5 \mathrm{~nm})$ was supplied by an argon ion laser. For the lowtemperature Raman measurements, the samples were placed in a closed-cycle helium refrigerator that controlled the temperature with a precision of $\sim 0.2 \mathrm{~K}$.

Calculations on molecular L-methionine were performed at the B3LYP/6-31G** level of theory with the GAMESS-UK package [63]. The geometry was optimized and confirmed to be a genuine minimum by a Hessian calculation. The rotational profiles around the various bonds were determined by varying the corresponding dihedral angle from $0^{\circ}$ to $360^{\circ}$ in steps of $10^{\circ}$, and this dihedral was kept fixed during optimization of the remaining structural parameters. Fig. 2 depicts the optimized geometry of the free molecule together with its optimized bond lengths. Note that in the gas-phase the molecule is not in the zwitterionic form. Raman intensities were calculated at the B3LYP/6-31G** level of theory with the Dalton [64] program. Additional calculations on the crystalline L-methionine were performed with the CRYSTAL $[65,66]$ package at the 

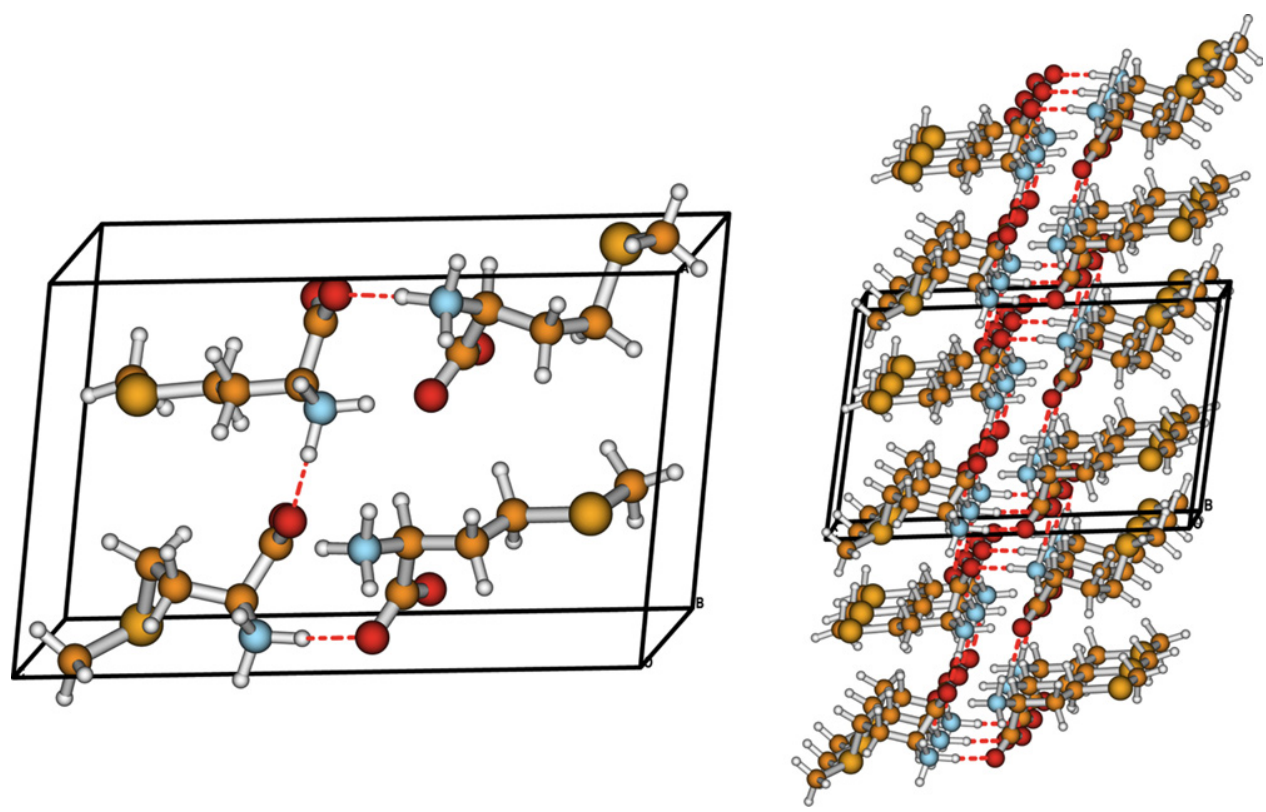

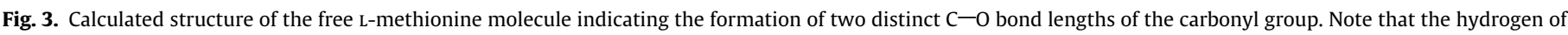
the $\mathrm{COOH}$ is transferred to the $\mathrm{NH}_{2}$ group in the crystal.

B3LYP/6-21G level of theory. The $k$-points were selected according to the procedure of Monkhorst and Pack [67] for an $8 \times 8 \times 8$ mesh. The experimental crystal structure $[21,22]$ was the starting point for the ion positions optimization (Fig. 3). The Raman frequencies were determined at the $\Gamma$ point.

Differential scanning calorimetry measurements, DSC, were performed using a Netzsch device between 190 and $360 \mathrm{~K}$ on powder samples mounted into a standard aluminum pan, using different scan speeds on cooling and heating.

Heat capacity measurements were performed using a Quantum Design PPMS equipped with the Quantum Design Heat Capacity option between $5 \mathrm{~K}<T<390 \mathrm{~K}$. Grains of the powder sample of $\mathrm{L}-$ methionine were mixed with the contact agent Apiezon $\mathrm{H}$ on the sample platform. To confirm the reproducibility of the data, three measurements were performed with each sample as follows: on heating starting from room temperature to $390 \mathrm{~K}$, then after the sample was cooled down to $5 \mathrm{~K}$, a second set of data was collected from 5 to $390 \mathrm{~K}$, and finally after cooling the sample to $100 \mathrm{~K}$, data were collected between 100 and $390 \mathrm{~K}$.

\section{Results}

3.1. Revealing molecular motions and proving conformational changes in the L-methionine molecules by correlating polarized Raman to DFT calculations

As shown in Fig. 4, computed Raman spectra and the experimental results compare favorably in terms of the overall spectral profile. The differences between the calculated geometrical features and vibrational frequencies of the free L-methionine molecule compared to those in the crystal are caused by formation of the $\mathrm{H}$-bonds in the latter. In the crystal the hydrogen of the $\mathrm{COOH}$ is transferred to the $\mathrm{NH}_{2}$ group, and in this zwitterionic form the $\mathrm{C}-\mathrm{O}$ bond lengths of the carbonyl group are almost identical with a bond length around $1.3 \AA$, see Fig. 3. In contrast, for the free molecule in the gas-phase, two distinct bond lengths of $1.21 \AA$ and $1.36 \AA$ (see Fig. 2). All other geometrical features are found to be rather similar. As a consequence of the formation of the zwitterion in the crystal that possesses $\mathrm{COO}^{-}$and $\mathrm{NH}_{3}{ }^{+}$groups, and forms hydrogen bonded networks, the differences in the calculated vibrational frequencies of the free molecule compared to those of the crystal are mostly concerned with the vibrations in which the $\mathrm{COOH}$ and $\mathrm{NH}_{2}$ groups participate. In particular the $\mathrm{NH}$ stretch and $\mathrm{NH}_{2}$ bending modes are affected. The $\mathrm{COO}-\mathrm{H}$ stretch and $\mathrm{NH}$ stretch modes are shifted from 3800 to $3500 \mathrm{~cm}^{-1}$ region for the free molecule to $3100-2800 \mathrm{~cm}^{-1}$ region in the crystal. Also, in the crystal, additional $\mathrm{NH}_{2}$ bending modes appear in $2000-1500 \mathrm{~cm}^{-1}$ region. Other small differences are found due to differences in basis set.

Now we turn to the detailed analysis of the different spectral regions of the Raman scattering data.

Fig. 5 presents the Raman spectra of L-methionine monocrystal in the $Z(Y Y) Z$ scattering geometry for selected temperatures (a) from 17 to $295 \mathrm{~K}$ and (b) from 300 to $375 \mathrm{~K}$. For amino acid crystals peaks appearing at $\omega<200 \mathrm{~cm}^{-1}$ are, in general terms, assigned as lattice modes, except for bands associated with torsion of the $\mathrm{CO}_{2}{ }^{-}$ group, $\tau\left(\mathrm{CO}_{2}\right)$ [40]. For L-methionine the lowest wavenumber band, at $\sim 129 \mathrm{~cm}^{-1}$, which is also the most intense peak in the spectrum taken at $17 \mathrm{~K}$, is assigned to an external (lattice) mode and the band

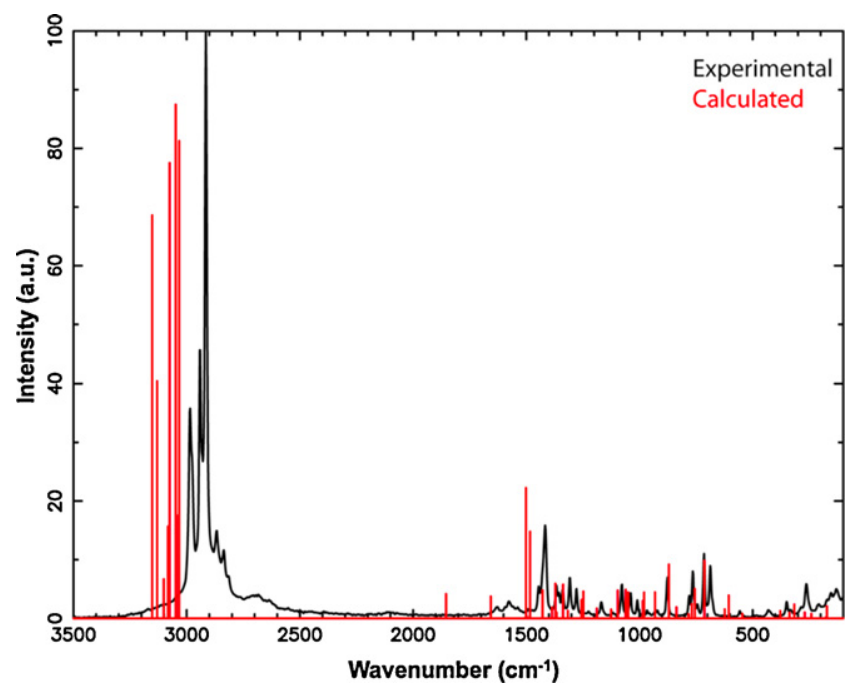

Fig. 4. Comparison of calculated and measured Raman spectra of L-methionine. 

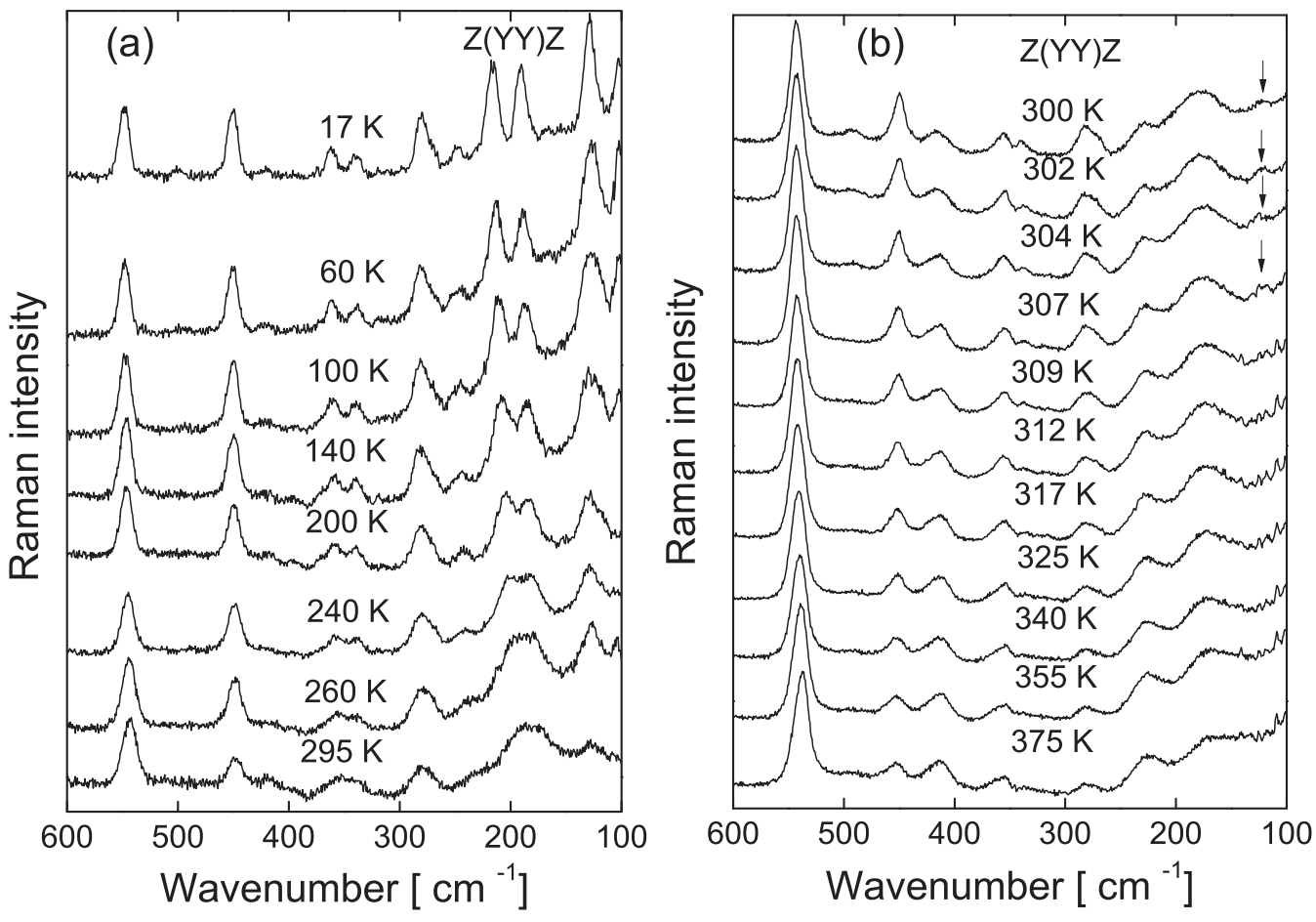

Fig. 5. Raman spectra of L-methionine crystal in the region between 600 and $100 \mathrm{~cm}^{-1}$ for $17-295 \mathrm{~K}$ (a) and for the $300-375 \mathrm{~K}$ (b) temperature ranges.

at $\sim 190 \mathrm{~cm}^{-1}$ to the $\tau\left(\mathrm{CO}_{2}^{-}\right)$. It is possible that for $\omega<100 \mathrm{~cm}^{-1}$ other bands associated with external modes exit, however due to the shoulder of the laser line, occurring just below $90 \mathrm{~cm}^{-1}$, all opportunity to observe Raman peaks in this region was eliminated. In spite of this, and as described below, our understanding of the already reported phase transition at $307 \mathrm{~K}$ was not jeopardized, and in addition we were able to evidence changes in the molecular conformation at lower temperatures.

In the low temperature range, the positions of the band associated with $\tau\left(\mathrm{CO}_{2}{ }^{-}\right)$as well as the nearby peak located at $196 \mathrm{~cm}^{-1}$ (at room temperature) change significantly from 17 to $295 \mathrm{~K}$. Moreover, the low intensity band at $238 \mathrm{~cm}^{-1}$, assigned as torsion of CC, $\tau(\mathrm{CC})$, and the CSC bending, $\delta(\mathrm{CSC})$, located at $281 \mathrm{~cm}^{-1}$, can be observed. Bands of low intensity observed at $\sim 350 \mathrm{~cm}^{-1}$ are assigned as skeleton bending, $\delta($ skel $)$, and the peak observed at $\sim 448 \mathrm{~cm}^{-1}$ as the $\mathrm{NH}_{3}{ }^{+}$torsion, $\tau\left(\mathrm{NH}_{3}\right)$ [14]. In some cases the study of this band is interesting because it gives information on the $\mathrm{H}$-bonds of the system. For instance, a comparative investigation of the behavior of $\tau\left(\mathrm{NH}_{3}\right)$ with pressure showed that for L-threonine and taurine the wavenumber increases with pressure, while for L-alanine the wavenumber of $\tau\left(\mathrm{NH}_{3}\right)$ decreases on compression [68]. In L-alanine, this behavior was understood as a deformation of the H-bond network under applied pressure. On the other hand, the observation of wavenumber change of the $\tau\left(\mathrm{NH}_{3}\right)$ on DL-serine was associated with molecular rearrangements in the unit cell through changes in the H-bonding interactions [6]. In the present study, however, no great change is observed on the wavenumber of the $\tau\left(\mathrm{NH}_{3}\right)$ mode, indicating subtle, if any, changes related to the $\mathrm{NH}_{3}{ }^{+}$-group in the $17-300 \mathrm{~K}$ interval. Such behavior, in fact, is very similar to that observed for $\alpha$-glycine, where the wavenumber of the $\tau\left(\mathrm{NH}_{3}\right)$ mode is almost constant in a $300 \mathrm{~K}$ interval, indicating no significant change in H-bond length [69].

In Fig. 5 the peak observed at $543 \mathrm{~cm}^{-1}$ is associated to the $\mathrm{CO}_{2}$ rocking vibration, $r\left(\mathrm{CO}_{2}\right)$. For this band a linear behavior of the wavenumber with temperature is also observed, although the variation of wavenumber in the temperature interval investigated is greater than the variation of wavenumber of $\tau\left(\mathrm{NH}_{3}\right)$ mode. As mentioned previously, in the $Z(Y Y) Z$ scattering geometry, the band at $129 \mathrm{~cm}^{-1}$, marked by a down arrow in Fig. 5 , is the most intense in the spectrum of L-methionine in the spectral range from 600 to $100 \mathrm{~cm}^{-1}$ and, on heating, it is still visible up to $\sim 307 \mathrm{~K}$. For temperatures higher than $309 \mathrm{~K}$, however, this band is no longer observed. Note that the other bands, although lower in intensity, remain clearly visible up to $T=375 \mathrm{~K}-$ compare also, the intensity of the band assigned to the lattice vibration and the band associated with $r\left(\mathrm{CO}_{2}\right)$. Therefore we can conclude that the intensity decrease leading to the disappearance of the peak at $129 \mathrm{~cm}^{-1}$ is intrinsic to this band. So, this particular band, associated with a lattice mode of the crystal, vanishes when $T \rightarrow 307 \mathrm{~K}$, thus implying that the symmetry of the unit cell is changing. In other words, the phase transition observed in the previous calorimetric measurements on powder samples can be related to changes of this particular lattice mode in the crystal.

At lower temperatures, no further changes in the Raman spectra that could be associated with structural or even conformational modification in L-methionine crystal were observe in the spectral region depicted in Fig. 5. Therefore, in order to analyze the behavior of the material at low temperatures, i.e. for $T<300 \mathrm{~K}$, we have measured the Raman spectra at $Z(Y Y) Z$ and $Z(Y X) Z$ scattering geometries for other spectral regions. Fig. 6(a) and (b) presents the Raman spectra of L-methionine monocrystal in the spectral range $1050-600 \mathrm{~cm}^{-1}$ for selected temperatures in the $Z(Y Y) Z$ and $Z(Y X) Z$ scattering geometries, respectively. This region is characterized by vibrations assigned to $\mathrm{CS}$ stretching, $\nu(\mathrm{CS}), \mathrm{CO}_{2}{ }^{-}$wagging and bending, $\omega\left(\mathrm{CO}_{2}{ }^{-}\right)$and $\delta\left(\mathrm{CO}_{2}{ }^{-}\right)$, and to $\mathrm{CH}_{3}$ and $\mathrm{NH}_{3}{ }^{+}$, rocking, $\rho\left(\mathrm{CH}_{3}\right)$ and $\rho\left(\mathrm{NH}_{3}{ }^{+}\right)[16,18]$. As expected the $Z(Y Y) Z$ spectra arising from a totally symmetric representation have a signal-to-noise relationship higher than the spectra from the other scattering geometry. Besides, an intensity increase is observed for both set of spectra on cooling, including the bands at 721 and $766 \mathrm{~cm}^{-1}$, which are associated with the $v(\mathrm{CS})$, and the bands observed at 806 and $877 \mathrm{~cm}^{-1}$, associated with the $v(\mathrm{CC})$. No further notable changes are observed in this spectral region. 
(a)

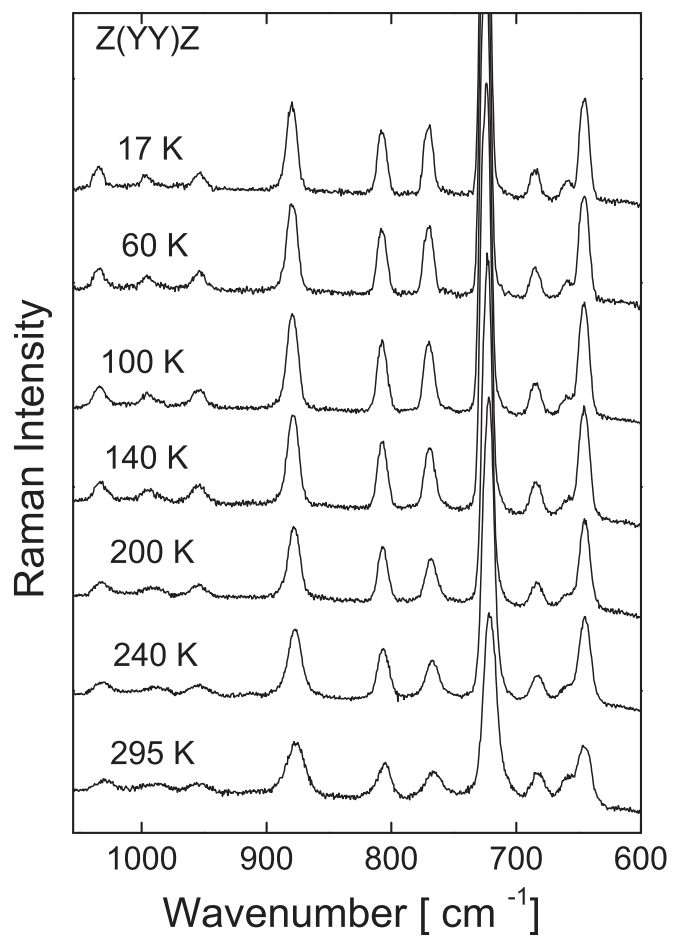

(b)

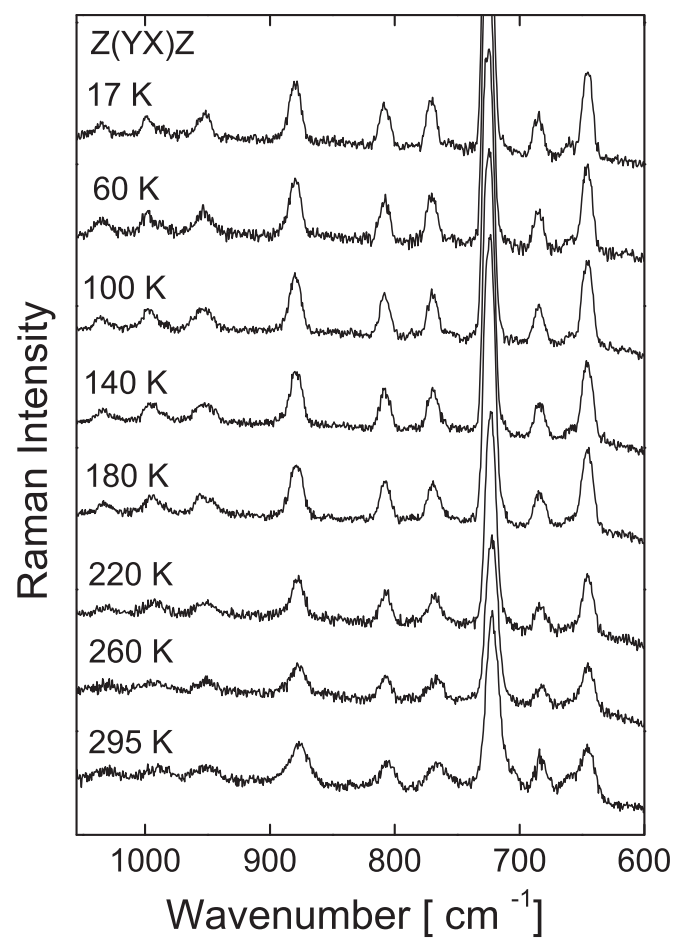

Fig. 6. Low temperature Raman spectra of L-methionine crystal in the region between 1050 and $600 \mathrm{~cm}^{-1}$ for the $Z(Y Y) Z(a)$ and $Z(Y X) Z(b)$ scattering geometries.

Fig. 7 shows the Raman spectra of L-methionine monocrystal for selected temperatures in the two selected scattering geometries for the spectral range $1550-1200 \mathrm{~cm}^{-1}$, where, among others, the bands associated with the $\mathrm{CH}_{2}, \mathrm{CH}$ and $\mathrm{CH}_{3}$ symmetric bending, $\delta\left(\mathrm{CH}_{2}\right), \delta(\mathrm{CH})$ and $\delta_{\mathrm{s}}\left(\mathrm{CH}_{3}\right)$ are expected to be observed [16,18]. Although an apparent peak splitting between 1300 and $1400 \mathrm{~cm}^{-1}$ seems to occur on cooling, at $295 \mathrm{~K}$ this spectral region can be already fitted by four peaks at $1321,1338,1354$ and $1363 \mathrm{~cm}^{-1}$ in the $Z(Y Y) Z$ scattering geometry and at 1323, 1341, 1356 and $1365 \mathrm{~cm}^{-1}$ in the $Z(Y X) Z$ scattering geometry. Nevertheless, it is very unambiguous that the peak assigned to the $\delta_{\mathrm{s}}\left(\mathrm{CH}_{3}\right)$, observed at $1355 \mathrm{~cm}^{-1}$, becomes clearly evident at about $240 \mathrm{~K}$ in the $Z(Y Y) Z$ (a)

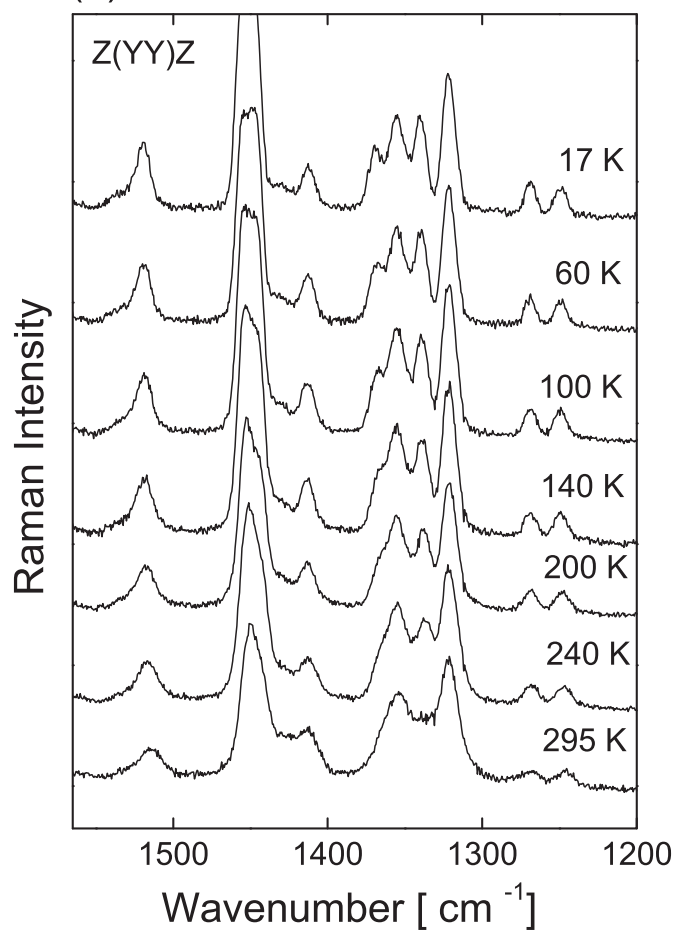

(b)

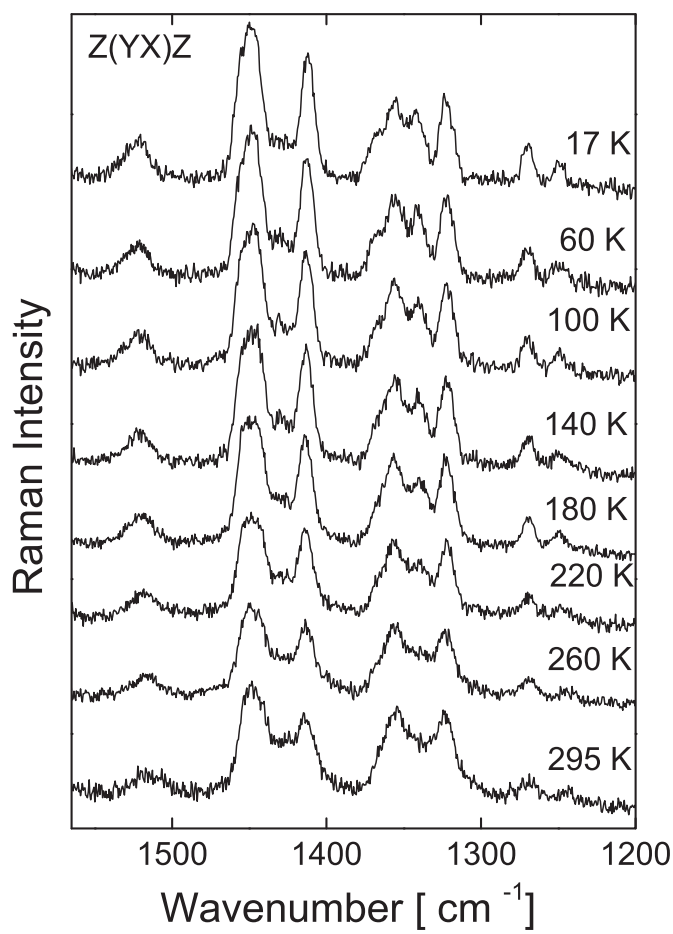

Fig. 7. Low temperature Raman spectra of L-methionine crystal in the region between 1550 and $1200 \mathrm{~cm}^{-1}$ for the $Z(Y Y) Z(a)$ and $Z(Y X) Z$ (b) scattering geometries. 
(a)

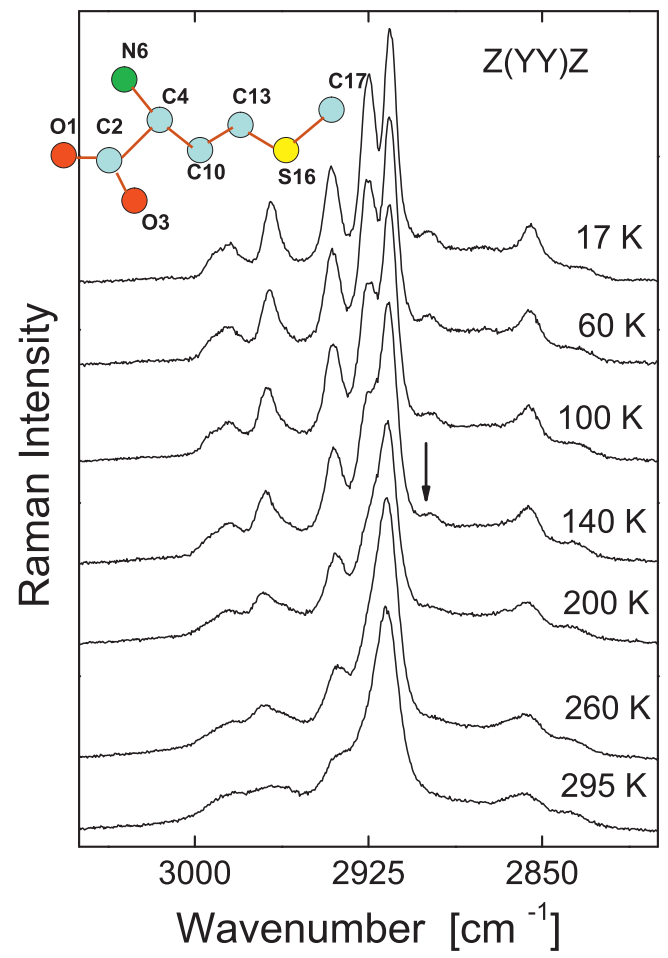

(b)

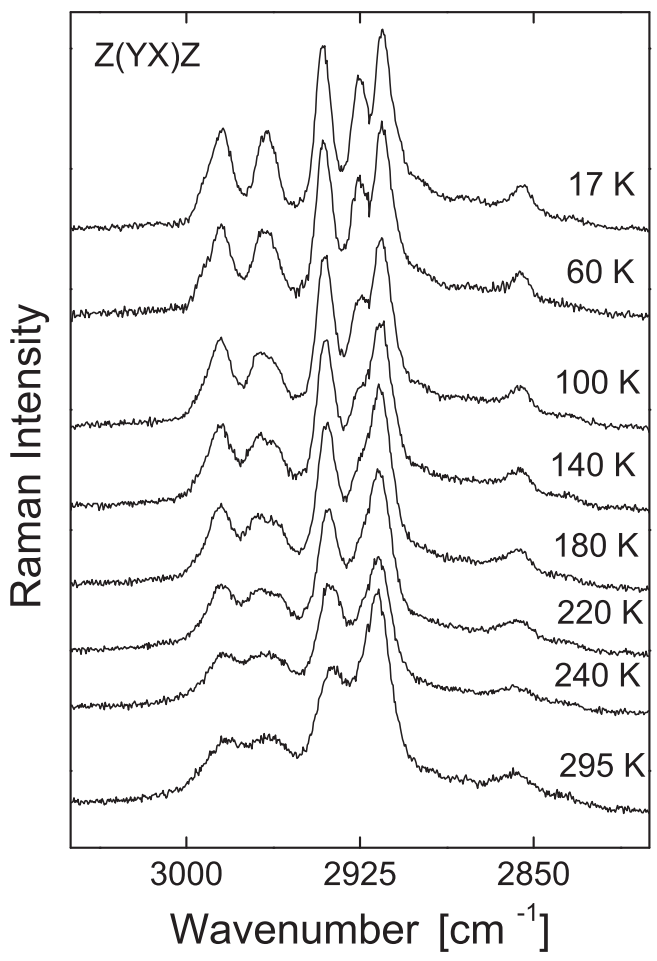

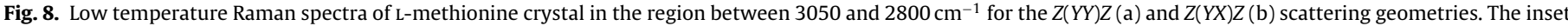
presents the representation of an L-methionine molecule (hydrogen atoms not shown) with atom numbering - see text.

scattering geometry and at about $220 \mathrm{~K}$ in the spectrum taken in the $Z(Y X) Z$ geometry, whereas at about $140 \mathrm{~K}$, the peak at $1455 \mathrm{~cm}^{-1}$, assigned as $\delta_{\mathrm{as}}\left(\mathrm{CH}_{3}\right)$, is visibly distinguished (Table 1$)$.

Fig. 8 presents the Raman spectra of L-methionine crystal in the high wavenumber spectral region for both $Z(Y Y) Z$ and $Z(Y X) Z$ scattering geometries for selected temperatures. No band was observed for wavenumbers higher than $3200 \mathrm{~cm}^{-1}$. This region, dominated by the $\mathrm{CH}$ and $\mathrm{CH}_{2}$ stretching vibrations, gives important insight on the conformation of the molecules in the unit cell as already pointed out in Ref. [6]. In our study, changes around $150 \mathrm{~K}$ were observed for several bands. In particular, it is observed that a band at $\sim 2900 \mathrm{~cm}^{-1}$ appears on cooling in the $Z(Y Y) Z$ spectra taken at $140 \mathrm{~K}$ (down arrow in Fig. 8(a)). Moreover, in both geometries we observe the splitting of the bands centered around $2925 \mathrm{~cm}^{-1}$. Even if one can argue that these bands are already present at room temperature in both geometries, the increase of their intensity is remarkable. Therefore these observations reveal that conformational changes are triggered at $140 \mathrm{~K}$, and that such changes can be considered as precursors of the phase transition observed at $307 \mathrm{~K}$. In other words, on heating the molecules begin to reorganize and gain motional freedom, and as the temperature approaches the transition temperature, the distance range of this cooperation increases, leading to correlated interactions, and consequently, a sudden change of order at the phase transition temperature.

Finally, in Fig. 9 we present the wavenumber vs. temperature plot for the modes appearing in the $Z(Y Y) Z$ scattering geometry in the spectral range $550-100 \mathrm{~cm}^{-1}$ in order to illustrate the discontinuity of a mode at $307 \mathrm{~K}$.

\subsection{Thermal behavior: analyzing the structural phase transition and the conformational changes observed in L-methionine}

As already mentioned, a phase transition at about $307 \mathrm{~K}$ in Lmethionine, characterized by a very broad peak in the thermal analysis in powder samples has been well documented [16,17]. However, neither the origin of such observation has been fully explored, nor has the reproducibility of the data been verified. Therefore, in order to better understand the origin of the conformational change observed in our Raman results, we have performed

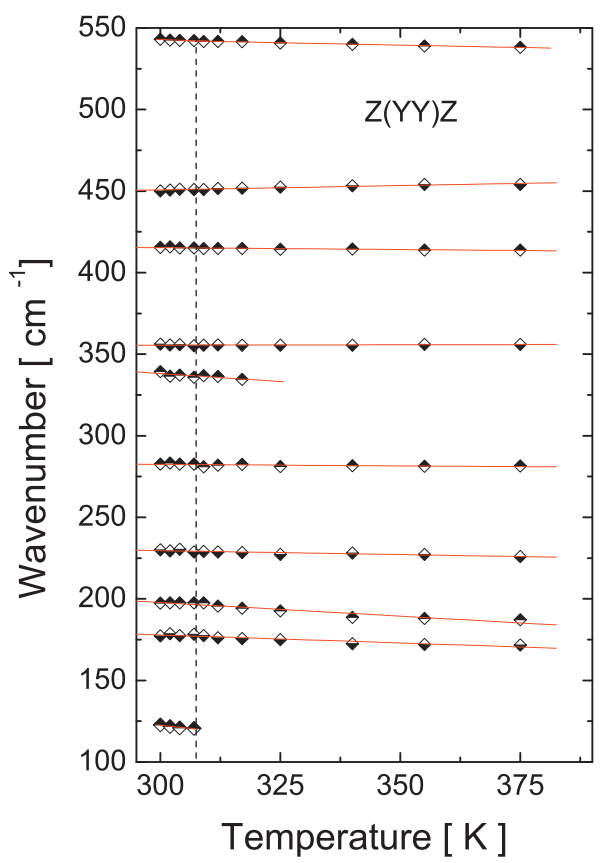

Fig. 9. Wavenumber vs. temperature plot for modes of L-methionine in the spectral range $550-100 \mathrm{~cm}^{-1}$ for the $Z(Y Y) Z$ scattering geometry showing the disappearance of a band associated with the lattice mode at $\sim 307 \mathrm{~K}$. The dashed line represents the temperature where the crystal undergoes a phase transition. 


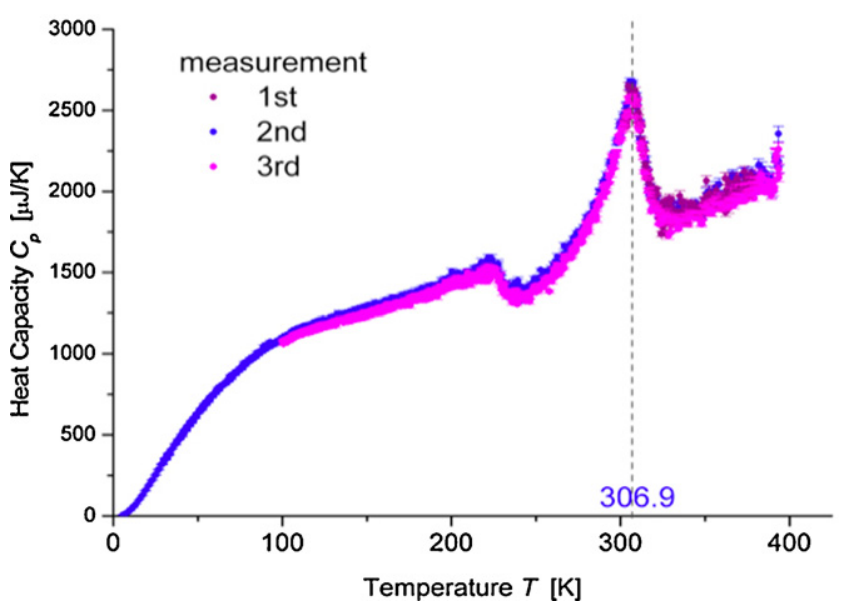

Fig. 10. Heat capacity, $C_{\mathrm{p}}$, of L-methionine, showing that in the polycrystalline sample a broad transition is observed between $275 \mathrm{~K}$ and $325 \mathrm{~K}$ with a maximum at $307.0 \pm 0.2 \mathrm{~K}$.

a series of measurements using powder samples on an extended temperature range, $5 \mathrm{~K}<T<320 \mathrm{~K}$.

Heat capacity $\left(C_{\mathrm{p}}\right)$ measurements on L-methionine powder samples are reported in Fig. 10; in agreement with the previous work [16], the broad and strong peak indicating a phase transition extended over a wide temperature ranging from about 250 to $325 \mathrm{~K}$ with a maximum at $306.9 \pm 0.2 \mathrm{~K}$ was reproduced. However, unlike Ref. [16], a second anomaly was observed at lower temperatures about $220 \mathrm{~K}$. This change in the $C_{\mathrm{p}}$ coincides to the temperature where the Raman peak assigned to the $\delta\left(\mathrm{CH}_{3}\right)$ becomes noticeable in the Raman spectra. Therefore we can argue that due to the malleability of the $\mathrm{CH}_{3}$-group, structural relaxation can occur and that at ambient conditions L-methionine is either in a metastable state or shows differences in the local structure, yielding to some disorder in the form of a distribution of energy barriers that are altered on cooling. From this line of argument, we deduce that the changes observed in the thermodynamical response as well as in the vibrational modes of L-methionine at lower temperatures are related to variations of the interactions of the L-methionine molecules with the crystalline environment, similarly to the response previously observed in L-cysteine [12] and L-alanine [39].

The DSC data, shown in Fig. 11, were collected as follows. We started by heating the sample from $295 \mathrm{~K}$ up to $360 \mathrm{~K}$ (red curve) at $2 \mathrm{~K} / \mathrm{min}$ and, subsequently, performing consecutive cooling and heating cycles with scan speeds of $2,4,8$ and $16 \mathrm{~K} / \mathrm{min}$. The peak observed in the $C_{\mathrm{p}}$-measurements was also clearly observed in the temperature range from $260 \mathrm{~K}$ to $320 \mathrm{~K}$. By extrapolating to $0 \mathrm{~K} / \mathrm{min}$ scan rate $[70,71]$, a transition temperature of $T_{0}=307.0 \pm 0.3 \mathrm{~K}$ was determined. By calculating the changes in enthalpy and entropy [70], further information on the mechanisms involved in the energetic change as well as the characterization of the transition as a first order phase-transition was obtained. All parameters are listed in Table 2. In Table 3 we furnish a summary of results obtained in the present work, as well as the type of material (crystal or powder) utilized in the experiments and the temperature of the phase transition observed by the several procedures.

\section{Discussion}

The modifications verified in the Raman spectra of L-methionine at low temperatures are very different from those observed through high pressure experiments [72]. For example, in the spectral region $650-700 \mathrm{~cm}^{-1}$, where the bands associated with the bending of CCO [14] and/or rocking of the $\mathrm{CH}_{2}$ [18] are expected, it was observed the appearance of a very intense band, up to now, one of

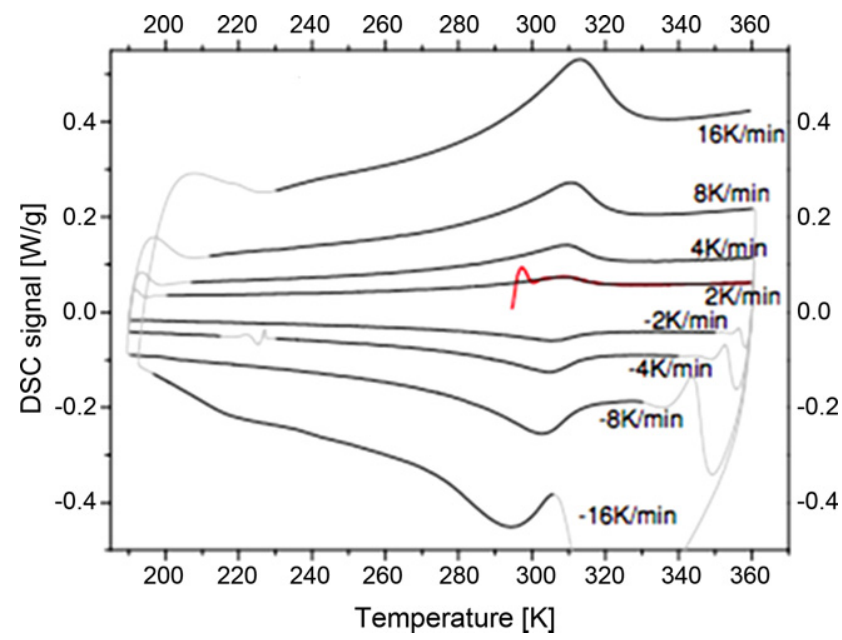

Fig. 11. DSC-curves of a $24.708 \pm 0.001 \mathrm{mg}$ of polycrystalline L-methionine at heating rates of $2,4,8$ and $16 \mathrm{~K} / \mathrm{min}$ between 260 and $360 \mathrm{~K}$. A phase transition is observed around $300 \mathrm{~K}$. Since the heating/cooling system needs some time for stabilization, the features observed at the beginning and at the end of the heating and cooling cycles, and represented with light gray color, are due to unstable oven temperatures only. (For interpretation of the references to color in the text, the reader is referred to the web version of the article.)

the most impressive phenomena reported in the literature related to proteic amino acids. Such an exceptional effect, however, is not seen here in the whole temperature range exploited. Therefore, the modification verified by Raman spectroscopy at high pressure is very particular to the change of that thermodynamic parameter.

On the other hand, even if interactions leading to conformational changes are small, the variation in the system energy are most likely observable in the $C_{\mathrm{p}}$ results, but expected to clearly manifest themselves in the dynamical measurements over a broad energy range. This is indeed what was demonstrated here by combining Raman scattering to thermal analysis. In other words, our low temperature measurements, presenting few and slight modifications in the Raman spectra of L-methionine crystal, do not indicate that this crystalline amino acid is undergoing a structural phase transition such as the one clearly observed under applied hydrostatic pressure conditions or even at $T=307 \mathrm{~K}$, when lattice modes changes are observed. Although no clear modification has been observed in the low wavenumber region where we expect to find lattice vibrations, and although no impressive modification has been detected in the $650-700 \mathrm{~cm}^{-1}$ region, some changes were revealed in certain internal modes. This result can be indeed fully understood as follows. At room temperature, two conformers of L-methionine, A and $B$, are present in the crystalline unit cell [14]. In the A conformer the torsion of lateral chains is given by $\chi^{1}=\tau\left[N-C^{2}-C^{3}-C^{4}\right]=166^{\circ}$; $\chi^{2}=\tau\left[C^{2}-C^{3}-C^{4}-S\right]=174^{\circ} ; \chi^{3}=\tau\left[C^{3}-C^{4}-S-C^{5}\right]=180^{\circ}$ (where $C^{2}$ is the $\alpha$ carbon, $\mathrm{C}^{3}$ and $\mathrm{C}^{4}$ are between the $\alpha$ carbon and sulfur atom, and $\mathrm{C}^{5}$ is the carbon of the $\mathrm{CH}_{3}$ group, see Fig. 1(b)). On the other hand, for conformer $\mathrm{B}$ the corresponding torsional angles are $\chi^{1}=166^{\circ} ; \chi^{2}=174^{\circ} ; \chi^{3}=74^{\circ}$. When the crystal undergoes the high temperature phase transition, at about $307 \mathrm{~K}$, the monoclinic structure is conserved but the conformations of the molecules A and B are changed. Therefore the variation of intensities of the low frequency modes can be associated with such conformational modification. Additionally, as shown in Fig. 8, on cooling the band at $\sim 2925 \mathrm{~cm}^{-1}$ gains in intensity between room temperature and $140 \mathrm{~K}$, and from previously calculated vibrational spectra [18] of seven possible (stable) configurations for L-methionine, only one configuration allows for the observation of a band at $2926 \mathrm{~cm}^{-1}$. This particular configuration is characterized by the torsional angles: $\chi^{1}=-60^{\circ} ; \chi^{2}=180^{\circ}$ and $\chi^{3}=180^{\circ}$. Therefore our results imply that on cooling at least one of the two conformers 
Table 1

Experimental values for $\omega(295 \mathrm{~K}), \omega(17 \mathrm{~K})$ and coefficients $\omega_{0}$ and $\alpha$ for the linear fitting $\omega=\omega_{0}+\alpha \cdot T$ for L-methionine crystal at low temperatures.

\begin{tabular}{|c|c|c|c|c|c|c|c|c|}
\hline \multicolumn{4}{|l|}{$Z(Y Y) Z$ geometry } & \multicolumn{4}{|l|}{$Z(Y X) Z$ geometry } & \multirow[t]{2}{*}{ Assignments } \\
\hline$\omega(295 \mathrm{~K})\left(\mathrm{cm}^{-1}\right)$ & $\omega(17 \mathrm{~K})\left(\mathrm{cm}^{-1}\right)$ & $\omega_{0}\left(\mathrm{~cm}^{-1}\right)$ & $\alpha\left(\mathrm{cm}^{-1} / \mathrm{K}\right)$ & $\omega(295 \mathrm{~K})\left(\mathrm{cm}^{-1}\right)$ & $\omega(17 \mathrm{~K})\left(\mathrm{cm}^{-1}\right)$ & $\omega_{0}\left(\mathrm{~cm}^{-1}\right)$ & $\alpha\left(\mathrm{cm}^{-1} / \mathrm{K}\right)$ & \\
\hline \multirow[t]{2}{*}{127} & \multirow[t]{2}{*}{129} & \multirow[t]{2}{*}{28,5} & \multirow[t]{2}{*}{-0.0034} & \multirow[t]{2}{*}{121} & 127 & 125.4 & -0.0218 & Lattice \\
\hline & & & & & 167 & 167.3 & -0.0164 & Lattice \\
\hline 178 & 190 & 191.7 & -0.0424 & 171 & 186 & 187.7 & -0.0514 & $\tau\left(\mathrm{CO}_{2}^{-}\right)$ \\
\hline 196 & 216 & 218.1 & -0.0724 & 192 & 215 & 216.6 & -0.0795 & Lattice \\
\hline 238 & 248 & 250.1 & -0.0372 & & & & & $\tau(\mathrm{CC})$ \\
\hline 281 & 282 & 282.1 & -0.0055 & 282 & 279 & 279.0 & 0.0106 & $\delta(\operatorname{CSC})$ \\
\hline \multirow[t]{2}{*}{338} & \multirow[t]{2}{*}{340} & \multirow[t]{2}{*}{339.8} & \multirow[t]{2}{*}{-0.0004} & 337 & 341 & 339.4 & -0.0058 & $\delta($ skel $)$ \\
\hline & & & & 358 & 368 & 368.7 & -0.0382 & $\delta($ skel $)$ \\
\hline \multirow[t]{2}{*}{354} & \multirow[t]{2}{*}{362} & \multirow[t]{2}{*}{362.9} & \multirow[t]{2}{*}{-0.0262} & & & & & $\delta($ skel $)$ \\
\hline & & & & 419 & 421 & 420.1 & -0.0026 & $\tau\left(\mathrm{NH}_{3}{ }^{+}\right)$ \\
\hline 447 & 451 & 451.4 & -0.0117 & 448 & 451 & 452.5 & -0.0136 & $\tau\left(\mathrm{NH}_{3}{ }^{+}\right)$ \\
\hline 543 & 549 & 549.1 & -0.0178 & 546 & 551 & 551.2 & -0.0176 & $r\left(\mathrm{CO}_{2}^{-}\right)$ \\
\hline 645 & 645 & 645.8 & -0.0025 & 645 & 646 & 645.8 & -0.002 & $v(\mathrm{CS})$ \\
\hline 659 & 660 & 660.0 & -0.0014 & 660 & 660 & 660.6 & -0.003 & $v(\mathrm{CS})$ \\
\hline 682 & 685 & 685.2 & -0.0111 & 683 & 685 & 685.3 & -0.0098 & $\omega\left(\mathrm{CO}_{2}^{-}\right)$ \\
\hline 721 & 725 & 725.9 & -0.0151 & 722 & 725 & 726.2 & -0.0142 & $\delta\left(\mathrm{CO}_{2}^{-}\right)$ \\
\hline 766 & 770 & 771.2 & -0.0159 & 766 & 771 & 771.5 & -0.0171 & $v(\mathrm{CS})$ \\
\hline 806 & 808 & 808.0 & -0.0059 & 806 & 808 & 808.7 & -0.0066 & $v(\mathrm{CC})$ \\
\hline 877 & 880 & 880.2 & -0.0115 & 877 & 880 & 880.6 & -0.0117 & $v(\mathrm{CC})$ \\
\hline 954 & 954 & 954.2 & 0.0005 & 950 & 953 & 953.6 & -0.0118 & $\rho\left(\mathrm{CH}_{3}\right)$ \\
\hline 989 & 996 & 997.4 & -0.0278 & 989 & 997 & 998.7 & -0.0269 & $\rho\left(\mathrm{NH}_{3}{ }^{+}\right)$ \\
\hline 1029 & 1035 & 1035.3 & -0.0178 & 1032 & 1035 & 1035.6 & -0.0162 & $v_{\mathrm{s}}(\mathrm{CN})$ \\
\hline 1245 & 1249 & 1250.4 & -0.0137 & 1244 & 1249 & 1250.4 & -0.02 & $\delta\left(\mathrm{CH}_{2}\right)$ \\
\hline 1268 & 1269 & 1269.3 & -0.0047 & 1270 & 1270 & 1570.3 & -0.0023 & $\delta(\mathrm{CH})$ \\
\hline 1321 & 1322 & 1321.4 & 0.0004 & 1323 & 1322 & 1321.8 & 0.0026 & $\omega\left(\mathrm{CH}_{2}\right)$ \\
\hline 1338 & 1340 & 1340.6 & -0.0105 & 1341 & 1342 & 1340.8 & -0.001 & $\omega\left(\mathrm{CH}_{2}\right)$ \\
\hline 1354 & 1355 & 1355.8 & -0.0049 & 1356 & 1356 & 1355.9 & 0.0014 & $\delta_{\mathrm{s}}\left(\mathrm{CH}_{3}\right)$ \\
\hline 1363 & 1369 & 1370.7 & -0.0266 & 1365 & 1368 & 1369.0 & -0.0089 & $\delta_{\mathrm{s}}\left(\mathrm{CH}_{3}\right)$ \\
\hline 1412 & 1413 & 1413.0 & -0.0014 & 1413 & 1412 & 1412.6 & 0.0033 & $v(\mathrm{CC})$ \\
\hline 1425 & 1429 & 1429.8 & -0.0191 & 1428 & 1428 & 1429.4 & -0.0034 & $\delta_{\mathrm{as}}\left(\mathrm{CH}_{3}\right)$ \\
\hline 1444 & 1448 & 1448.1 & -0.017 & 1444 & 1448 & 1448.1 & -0.0161 & $\delta_{\mathrm{as}}\left(\mathrm{CH}_{3}\right) / \delta_{\mathrm{s}}\left(\mathrm{CH}_{2}\right)$ \\
\hline 1451 & 1456 & 1456.5 & -0.0174 & 1452 & 1456 & 1456.4 & -0.0147 & $\delta_{\text {as }}\left(\mathrm{CH}_{3}\right) / \delta_{\mathrm{s}}\left(\mathrm{CH}_{2}\right)$ \\
\hline \multirow[t]{2}{*}{1515} & 1520 & 1520.6 & -0.0154 & 1517 & 1523 & 1524.6 & -0.0253 & $v_{\mathrm{as}}(\mathrm{CN})$ \\
\hline & 1535 & 1535.0 & -0.0198 & & & & & \\
\hline 2837 & 2833 & 2833.5 & 0.0136 & & & & & $v_{\mathrm{s}}\left(\mathrm{CH}_{2}\right)$ \\
\hline 2858 & 2855 & 2855.2 & 0.0107 & 2858 & 2855 & 2854.9 & 0.0106 & $v_{\mathrm{s}}\left(\mathrm{CH}_{2}\right)$ \\
\hline 2917 & 2916 & 2915.5 & 0.0042 & 2917 & 2915 & 2914.8 & 0.0061 & $v_{\mathrm{as}}\left(\mathrm{CH}_{2}\right)$ \\
\hline \multirow[t]{2}{*}{2921} & \multirow[t]{2}{*}{2925} & 2925.2 & 0.0008 & \multirow[t]{2}{*}{2923} & \multirow[t]{2}{*}{2926} & 2925.4 & 0.0041 & $v(\mathrm{CH})$ \\
\hline & & 2929.5 & -0.029 & & & 2929.0 & -0.0216 & \\
\hline 2939 & 2941 & 2941.4 & -0.0102 & 2938 & 2941 & 2941.3 & -0.0119 & $v_{\mathrm{as}}\left(\mathrm{CH}_{2}\right)$ \\
\hline 2961 & & 2960.8 & 0.0013 & 2961 & 2966 & 2962.0 & -0.0047 & $v_{\mathrm{as}}\left(\mathrm{CH}_{3}\right)$ \\
\hline 2971 & 2967 & 2966.9 & 0.0151 & 2869 & 2985 & 2965.1 & 0.0383 & $v_{\mathrm{as}}\left(\mathrm{CH}_{3}\right)$ \\
\hline & & & & & & 2968.6 & 0.002 & \\
\hline 2987 & 2985 & 2984.8 & 0.0065 & 2984 & 2992 & 2985.8 & -0.0039 & $v_{\mathrm{as}}\left(\mathrm{CH}_{3}\right)$ \\
\hline & 2991 & 2990.9 & 0.0206 & & & & & \\
\hline
\end{tabular}

Table 2

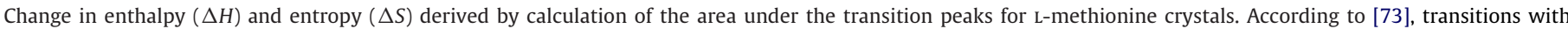
$\Delta S>1 \mathrm{~J} / \mathrm{mol} \mathrm{K}$, can be considered as first order phase transitions.

\begin{tabular}{|c|c|c|c|c|c|c|c|}
\hline Sample state & $\Delta T(\mathrm{~K} / \mathrm{min})$ & $T_{\text {onset }}(\mathrm{K})$ & $T_{\text {final }}(\mathrm{K})$ & $T_{\text {peak }}(\mathrm{K})$ & $\Delta S(\mathrm{~J} / \mathrm{mol} \mathrm{K})$ & $\Delta H \mathrm{~kJ} / \mathrm{mol})$ & Type of transition \\
\hline \multirow[t]{4}{*}{ Powder } & 2 & 243 & 332 & 307 & 2.4 & 7.7 & \multirow{4}{*}{$\begin{array}{l}\text { First } \\
\text { order }\end{array}$} \\
\hline & 4 & 238 & 332 & 307 & 2.4 & 8.0 & \\
\hline & 8 & 253 & 335 & 307 & 2.5 & 8.0 & \\
\hline & 16 & 263 & 340 & 307 & 2.4 & 7.8 & \\
\hline
\end{tabular}

of L-methionine is changing conformation. Furthermore, the intensity changes observed in the $\delta\left(\mathrm{CH}_{3}\right)$ around $220-240 \mathrm{~K}$ in the Raman data can be related to the transition observed by $C_{\mathrm{p}}$ measurements, which are extremely sensitive to the way atoms and molecules are bond in a solid. The jump observed around $220 \mathrm{~K}$ resembles the one observed in glassy systems, further confirming that on cooling, the crystalline structure of L-methionine evolves from an arrangement possessing a large distribution of $\mathrm{H}$-bonds to a more stable system.

Table 3

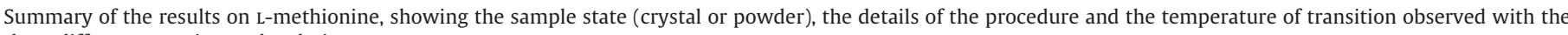
three different experimental techniques.

\begin{tabular}{|c|c|c|c|}
\hline Technique & Sample state & Details of procedure & Temperature of transition (K) \\
\hline Raman spectroscopy & Crystal & Heating & $307.0 \pm 0.2$ \\
\hline Heat capacity & Powder & Heating & $306.9 \pm 0.2$ \\
\hline DSC & Powder & $\begin{array}{l}\text { Heating and consecutive } \\
\text { cooling/heating cycles }\end{array}$ & $307.0 \pm 0.3$ \\
\hline
\end{tabular}




\section{Conclusion}

We can summarize our results as follows. In this report we have shown the Raman spectra of L-methionine crystal in the interval $100-3000 \mathrm{~cm}^{-1}$ for two scattering geometries at several temperatures, explaining the origin of a phase transition previously reported at $T=307 \mathrm{~K}$ and most importantly evidencing a conformational change of the molecule which is triggered around $240-220 \mathrm{~K}$ and finally happens in the interval 160-140 K. Change in the intensities of some Raman bands and a jump in the $C_{p}$ were associated with conformational changes of at least one of the two L-methionine conformers in the monoclinic unit cell. The high-temperature phase transition was related to a broad peak observed during the thermal analysis and to the disappearance of a lattice mode located at $129 \mathrm{~cm}^{-1}$ and thus implying that the symmetry of the unit cell in the high temperature phase changes. Finally, all vibrations could be assigned from comparison with the DFT calculated spectrum, showing that such studies are adequate to model the observed Raman vibrations of the amino acid L-methionine.

\section{Acknowledgments}

PTCF and HNB acknowledge with pleasure the critical reading of this work by Will P. Gates (Department of Civil Engineering, Monash University, Australia) and Robert C. Wimpory (Helmholtz Centre Berlin for Materials and Energy, Germany). The authors thank FUNCAP and CNPq, Brazilian agencies, for financial support. Part of the results presented in this work were obtained during the development of the Diplomarbeit of J. Fischer at the University of Kassel, and financially supported by the Helmholtz-Zentrum Berlin (HZB) through the groups of Prof. Dr. M. Ballauff and Dr. A. Kyriakopoulos. JF acknowledges Andrey Maljuk (HZB) for the thermal measurements. The research was further supported by the Deutsche Forschungsgemeinschaf (DFG project GZ: 444 BRA113/310/0-1). RWAH acknowledges the Netherlands Organization for Scientific Research (NWO/ECHO), grant 700.57.027, and the Zernike Institute for Advanced Materials ("Dieptestrategie" program) for financial support.

\section{References}

[1] E.V. Boldyreva, in: J.C.A. Boeyens, J.F. Ogilvie (Eds.), Models, Mysteries, and Magic of Molecules, Springer, Berlin, 2007, p. 169.

[2] P.T.C. Freire, J.A. Lima Jr., B.T.O. Abagaro, G.S. Pinheiro, J.A.F. Silva, J.M. Filho, F.E.A. Melo, in: D. de Caro (Ed.), Vibrational Spectroscopy, InTech, Rijeka, 2012, p. 37.

[3] L. Misoguti, V.S. Bagnato, S.C. Zilio, A.T. Varela, F.D. Nunes, F.E.A. Melo, J. Mendes Filho, Opt. Mater. 6 (1996) 147.

[4] K. Toyama, M. Tomoe, Y. Inoue, A. Sanbe, S. Yamamoto, Biol. Pharm. Bull. 31 (2008) 1852.

[5] A. Heredia, V. Meunier, I.K. Bdikin, J. Gracio, N. Balke, S. Jesse, A. Tselev, P.K. Agarwal, B.G. Sumpter, S.V. Kalinin, A.L. Kholkin, Adv. Funct. Mater. 22 (2012) 2996.

[6] C. Murli, R. Vasanthi, S.M. Sharma, Chem. Phys. 331 (2006) 77.

[7] S.A. Moggach, W.G. Marshall, S. Parsons, Acta Crystallogr. B 62 (2006) 815.

[8] I.E. Paukov, U.A. Kovalevskaya, V.A. Drebushchak, T.N. Drebushchak, E.V. Boldyreva, J. Phys. Chem. B 111 (2007) 9186

[9] V.S. Minkov, A.S. Krylov, E.V. Boldyreva, S.V. Goryainov, S.N. Bizyaev, A.N. Vtyurin, J. Phys. Chem. B 112 (2008) 8851.

[10] B.A. Kolesov, V.S. Minkov, E.V. Boldyreva, T.N. Drebushchak, J. Phys. Chem. B $112(2008) 12827$.

[11] V.S. Minkov, N.A. Tumanov, B.A. Kolesov, E.V. Boldyreva, S.N. Bizyaev, J. Phys. Chem. B 113 (2009) 5262

[12] H.N. Bordallo, E.V. Boldyreva, J. Fischer, M.M. Koza, T. Seydel, V.S. Minkov, V.A. Drebushchak, A. Kyriakopoulos, Biophys. Chem. 148 (2010) 34.

[13] V.S. Minkov, S.V. Goryainov, E.V. Boldyreva, C.H. Görbitz, J. Raman Spectrosc. $41(2010) 1748$.

[14] A. Grunenberg, D. Bougeard, J. Mol. Struct. 160 (1987) 27.

[15] B. Rossi, G. Mariotto, E. Ambrosi, H.L. Monaco, J. Raman Spectrosc. 40 (2009) 1844.

[16] A. Grunenberg, D. Bougeard, B. Schrader, Thermochim. Acta 77 (1984) 59.
[17] J.O. Hutchens, A.G. Cole, J.W. Stout, J. Biol. Chem. 239 (1964) 591.

[18] X. Cao, G. Fischer, J. Phys. Chem. A 106 (2002) 41.

[19] J.A. Lima Jr., P.T.C. Freire, F.E.A. Melo, J. Mendes, P.S. Pizani, J. Raman Spectrosc. $39(2008) 1076$

[20] B. Khawas, Acta Crystallogr. B 26 (1970) 1919.

[21] K. Torii, Y. Iitaka, Acta Crystallogr. B 29 (1973) S.62799.

[22] B. Dalhus, C.H. Görbitz, Acta Chem. Scand. 50 (1996) 544

[23] E. Martignoni, C. Tassorelli, G. Nappi, R. Zangaglia, C. Paccheti, F. Blandini, J. Neurol. Sci. 257 (2007) 31.

[24] R. Van Brummelen, D. Toit, Amino Acids 33 (2007) 57.

[25] R. Pal, D.B. Oien, F.Y. Ersen, J. Moskovitz, Exp. Brain Res. 180 (2007) 765.

[26] K.J. Barnham, M.I. Djuran, P.D. Murdoch, J.D. Ranford, P.J. Sadler, J. Chem. Soc Dalton Trans. 22 (1995) 3721.

[27] H.D. Bernstein, M.A. Poritz, K. Strub, P.J. Hoben, S. Brenner, P. Walter, Nature 340 (1989) 482.

[28] K.T. O’Neil, S. Erickson-Viitanen, W.F. DeGrado, J. Biol. Chem. 264 (1989) 14571.

[29] J.T. Edsall, J. Chem. Phys. 5 (1937) 225.

[30] E. Vass, M. Hollósi, F. Besson, R. Buchet, Chem. Rev. 103 (2003) 1917.

[31] Y. Xie, D. Zhang, D. Ben-Amotz, Anal. Biochem. 373 (2007) 154.

[32] R. Maoz, J. Sagiv, D. Degenhardt, H. Möhwald, P. Quint, P. Supramolecular, Science 2 (1995) 1.

[33] H. Sato, R. Murakami, J. Zhang, K. Mori, I. Takahashi, H. Terauchi, I. Noda, Y. Ozaki, Macromol. Symp. 230 (2005) 158.

[34] J.H. da Silva, J.A. Lima Jr., P.T.C. Freire, V. Lemos, J. Mendes Filho, F.E.A. Melo, P.S Pizani, J. Fischer, B. Klemke, E. Kemner, H.N. Bordallo, J. Phys.: Condens. Matter 21 (2009) 415404.

[35] P. Chatzigeorgiou, N. Papakonstantopoulos, N. Tagaroulia, E. Pollatos, P. Xynogalas, K. Viras, J. Phys. Chem. B 114 (2010) 1294.

[36] C. Murli, S. Thomas, S. Venkateswaran, S.M. Sharma, Physica B 364 (2005) 233.

[37] H.N. Bordallo, E.V. Boldyreva, A. Buchsteiner, M.M. Koza, S. Landsgesell, J. Phys. Chem. B 112 (2008) 8748.

[38] F.M. Almeida, P.T.C. Freire, R.J.C. Lima, C.M.R. Remédios, J. Mendes Filho, F.E.A Melo, J. Raman Spectrosc. 37 (2006) 1296.

[39] J.M. de Souza, P.T.C. Freire, D.N. Argyriou, J.A. Stride, M. Barthès, W. Kalceff, H.N Bordallo, Chem. Phys. Chem. 10 (2009) 3337.

[40] J.A. Lima Jr., P.T.C. Freire, R.J.C. Lima, A.J.D. Moreno, J. Mendes, F.E.A. Melo, J. Raman Spectrosc. 36 (2005) 1076.

[41] P.F. Façanha Filho, X. Jiao, P.T.C. Freire, J.A. Lima Jr., A.O. dos Santos, P.F. Henry, F. Yokaichiya, E. Kremner, H.N. Bordallo, Phys. Chem. Chem. Phys 13 (2011) 6576.

[42] B.A. Kolesov, E.V. Boldyreva, J. Phys. Chem. B 111 (2007) 14387.

[43] H.N. Bordallo, B.A. Kolesov, E.V. Boldyreva, F. Juranyi, J. Am. Chem. Soc. (Communications) 129 (2007) 10984

[44] E.V. Boldyreva, Phase Trans. 82 (2009) 303.

[45] V.S. Minkov, N.A. Tumanov, R.Q. Cabrera, E.V. Boldyreva, Cryst. Eng. Commun. 12 (2010) 2551

[46] I.E. Paukov, Yu A. Kovalevskaya, E.V. Boldyreva, J. Therm. Anal. Calorim. 100 (2010) 295

[47] N.A. Tumanov, E.V. Boldyreva, B.A. Kolesov, A.V. Kurnosov, R.Q. Cabrera, Acta Crystallogr. B 66 (2010) 458.

[48] B.A. Kolesov, E.V. Boldyreva, J. Raman Spectrosc. 42 (2011) 696

[49] N.V. Surovtsev, V.K. Malinovsky, E.V. Boldyreva, J. Chem. Phys. 134 (2011) 045102.

[50] B.A. Zakharov, B.A. Kolesov, E.V. Boldyreva, Phys. Chem. Chem. Phys. 13 (2011) 13106.

[51] N.A. Tumanov, E.V. Boldyreva, Acta Crystallogr. B 68 (2012) 412.

[52] R.O. Gonçalves, P.T.C. Freire, H.N. Bordallo, J.A. Lima Jr., F.E.A. Melo, J. Mendes Filho, D.N. Argyriou, R.J.C. Lima, J. Raman Spectrosc. 40 (2009) 958.

[53] J.M. de Souza, P.T.C. Freire, H.N. Bordallo, D.N. Argyriou, J. Phys. Chem. B 111 (2007) 5034

[54] M. Barthès, H.N. Bordallo, F. Dénoyer, J.-E. Lorenzo, J. Zaccaro, A. Robert, F. Zontone, Eur. Phys. J. B 37 (2004) 375-382.

[55] M. Barthès, A.F. Vik, A. Spire, H.N. Bordallo, J. Eckert, J. Phys. Chem. A 106 (2000) 5230.

[56] H.N. Bordallo, M. Barthès, J. Eckert, Phys. B. Cond. Matter 241 (1998) 1138

[57] B.B. Koleva, Vib. Spectrosc. 44 (2007) 30.

[58] E. Santoni, C. Jakopitsch, C. Obinger, G. Smulevich, Biopolymers 74 (2004) 46.

[59] A. Culka, J. Jehlicka, H.G. Edwards, Spectrochim. Acta A 77 (2010) 978.

[60] H. Lee, M.S. Kim, S.W. Suh, J. Raman Spectrosc. 22 (1991) 91.

[61] M.B. Mary, M. Umadevi, S. Pandiarajan, V. Ramakrishnan, Spectrochim. Acta A 60 (2004) 2643.

[62] A.M. Jenkins, R.A. Larsen, T.B. Williams, Spectrochim. Acta A 61 (2005) 1585.

[63] M.F. Guest, I.J. Bush, H.J.J. van Dam, P. Sherwood, J.M.H. Thomas, J.H. van Lenthe, R.W.A. Havenith, J. Kendrick, Mol. Phys. 103 (2005) 719

[64] DALTON, a molecular electronic structure program, Release 2.0, see http://www.kjemi.uio.no/software/dalton/dalton.html, 2005.

[65] R. Dovesi, R. Orlando, B. Civalleri, C. Roetti, V.R. Saunders, C.M. Zicovich-Wilson, Z. Kristallogr. 220 (2005) 220.

[66] R. Dovesi, V.R. Saunders, C. Roetti, R. Orlando, C.M. Zicovich-Wilson, F. Pascale F.B. Civalleri, K. Doll, N.M. Harrison, I.J. Bush, Ph. D’Arco, M. Llunell, CRYSTAL09 User's Manual, University of Torino, Torino, 2009.

[67] H.J. Monkhorst, J.D. Pack, Phys. Rev. B 13 (1976) 5188. 
[68] P.T.C. Freire, F.E.A. Melo, J. Mendes, R.J.C. Lima, A.M.R. Teixeira, Vib. Spectrosc. 45 (2007) 99.

[69] C. Murli, S.M. Sharma, S. Karmakar, S.K. Sikka, Chem. Phys. 331 (2006) 77.

[70] P. Navard, J.M. Haudin, J. Therm. Anal. 30 (1985) 405.
[71] P. Navard, J.M. Haudin, J. Therm. Anal. 30 (1985) 61.

[72] J.A. Lima Jr., P.T.C. Freire, F.E.A. Melo, V. Lemos, J. Mendes Filho, P.S. Pizani, J. Raman Spectrosc. 39 (2008) 1356.

[73] P. Ciapala, R. Jakubas, G. Bator, J. Zaleski, A. Pietraszko, M. Drozd, J. Baran, J. Phys.: Condens. Matter 9 (1997) 627. 